BRAVZULIAN JOURNAL

OF MEDICAL AND BIOLOGICAL RESFARCH

www.bjournal.com.br
ISSN 0100-879X

Volume 43 (4) 268-380 April 2011

BIOMEDICAL SCIENCES

AND

CLINICAL INVESTIGATION

Braz J Med Biol Res, April 2011, Volume 44(4) 311-318

doi: 10.1590/S0100-879X2011007500014

Evaluation of the antischistosomal activity of sulfated $\alpha$-D-glucan from the lichen Ramalina celastri free and encapsulated into liposomes

R.V.S. Araújo, M.R. Melo-Júnior, E.I.C. Beltrão, L.A. Mello, M. Iacomini, A.M.A. Carneiro-Leão, L.B. Carvalho Jr. and N.S. Santos-Magalhães

The Brazilian Journal of Medical and Biological Research is partially financed by

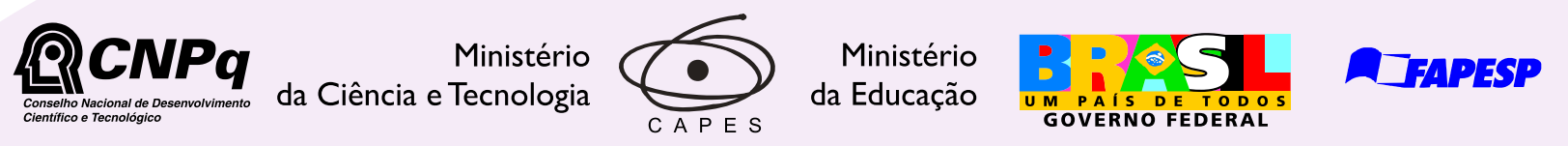

Institutional Sponsors
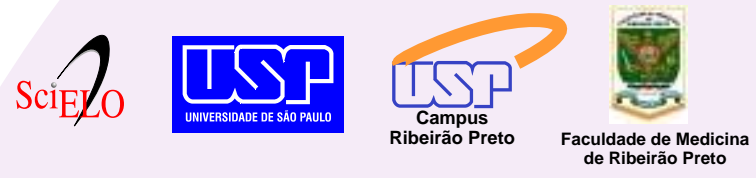
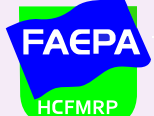

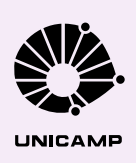

$\oplus$ SHIMADZU

GE Healthcare
Hotsite of proteomics metabolomics developped by:

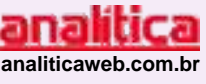

Thermo SCIENTIFIC 


\title{
Evaluation of the antischistosomal activity of sulfated $\alpha-D$-glucan from the lichen Ramalina celastri free and encapsulated into liposomes
}

\author{
R.V.S. Araújo ${ }^{1,4}$, M.R. Melo-Júnior ${ }^{1,2}$, E.I.C. Beltrão ${ }^{1,3}$, L.A. Mello5 ${ }^{5}$ M. lacomini6, \\ A.M.A. Carneiro-Leão ${ }^{7}$, L.B. Carvalho Jr. ${ }^{1,3}$ and N.S. Santos-Magalhães ${ }^{1,3}$ \\ ${ }^{1}$ Laboratório de Imunopatologia Keizo-Asami, Universidade Federal de Pernambuco, Recife, PE, Brasil \\ 2Departamento de Patologia, Universidade Federal de Pernambuco, Recife, PE, Brasil \\ ${ }^{3}$ Departamento de Bioquímica, Universidade Federal de Pernambuco, Recife, PE, Brasil \\ ${ }^{4}$ Associação Caruaruense de Ensino Superior, Caruaru, PE, Brasil \\ ${ }^{5}$ Departamento de Parasitologia, Universidade Federal de Minas Gerais, Belo Horizonte, MG, Brasil \\ ${ }^{6}$ Departamento de Bioquímica, Universidade Federal do Paraná, Curitiba, PR, Brasil \\ ${ }^{7}$ Departamento de Morfologia e Fisiologia Animal, Universidade Federal Rural de Pernambuco, Recife, PE, Brasil
}

\begin{abstract}
The antischistosomal activity of the sulfated polysaccharide $\alpha$-D-glucan (Glu.SO ${ }_{4}$ ) extracted from Ramalina celastri was evaluated after encapsulation into liposomes (Glu.SO 4 -LIPO) in Schistosoma mansoni-infected mice. The effect of treatment with Glu.SO $\mathrm{SO}_{4}$ and Glu.SO $\mathrm{SO}_{4}$-LIPO (10 mg/kg) on egg elimination, worm burden and hepatic granuloma formation was assessed using female albino Swiss mice, 35-40 days of age, weighing $25 \pm 2 \mathrm{~g}$, infected with 150 cercariae/animal (Biomphalaria glabrata, BH strain). Four groups $(\mathrm{N}=10)$ were studied, two controls (empty liposomes and $\mathrm{NaCl}$ ) and two treated groups (Glu.SO Glu.SO $\mathrm{S}_{4}$ ) using a single dose. Parasitological analysis revealed that $\mathrm{Glu}_{\text {.SO }}$-LIPO was as efficient as $\mathrm{Glu}_{\text {. }} \mathrm{SO}_{4}$ in reducing egg elimination and worm burden. Treatment with free $\mathrm{Glu}_{\text {. }} \mathrm{SO}_{4}$ and $\mathrm{Glu} . \mathrm{SO}_{4}$-LIPO induced a statistically significant reduction in the number of granulomas (62 and 63\%, respectively). Lectin histochemistry showed that wheat germ agglutinin intensely stained the egg-granuloma system in all treated groups. On the other hand, peanut agglutinin stained cells in the control groups, but not in the treated groups. The present results suggest a correlation between the decreasing number of hepatic egg-granulomas and the glycosylation profile of the egg-granuloma system in animals treated with free $\mathrm{Glu}_{\text {.SO }}$ or $\mathrm{Glu}_{\text {.SO }}$-LIPO.
\end{abstract}

Key words: Polysaccharide; a-D-glucan; Ramalina celastri; Liposomes; Schistosoma mansoni; Lectin histochemistry

\section{Introduction}

Schistosomiasis remains one of the most prevalent parasitic infections, involving major economic consequences and affecting many public health programs (1). Praziquantel and oxamniquine are currently the drugs of choice for the treatment of schistosomiasis (2-4); nevertheless a few reports have pointed out that some resistance to these drugs has emerged (5-7).

Parasite egg elimination, granuloma formation, disease severity, resistance to reinfection, and drug efficacy have been shown to be significantly dependent on the immunological factors of patients infected with Schistosoma (8-10). The prospect of having only a very limited number of therapeutic choices available for a disease affecting 200 million people is rather alarming (5). In this scenario, the development of new drugs or novel pharmaceutical dosage forms of old drugs is of great significance.

A series of studies have shown that numerous polysaccharides, including glucans from diverse biological sources, have immune potentiating activity (11). The immunomodulating effects of glucans involve macrophages, T-helper and natural killer cells, T-cell differentiation, the proliferative response of polymorphic nuclear cells, the production of interleukins and interferon, as well as an increase in phagocyte activity (12).

Correspondence: R.V.S. Araújo, Associação Caruaruense de Ensino Superior, Av. Portugal, 584, 55016-901 Caruaru, PE, Brasil. Fax: +55-81-2103-2004. E-mail: rosangela.vidal@gmail.com

Received August 2, 2010. Accepted January 6, 2011. Available online February 4, 2011. Published April 11, 2011. 
Lichens are promising sources of a-glucans, which are generally soluble in water and have a linear structure with glycoside linkages of the $\alpha-[1.3]$ and $\alpha-[1.4]$ type (13). Some cytotoxic effects against HeLa cells have been reported for an $\alpha-D-g l u c a n$ isolated from the lichen Ramalina celastri (14). This polysaccharide, which presents mainly a-[1.3], [1.4] linkages in its structure, has shown cytotoxic effects against HeLa cells, phagocytic activity, antitumor effects against sarcoma-180, and effects on peritoneal cell exudates. These features suggest a promising role of the $R$. celastri glucan as a biological response modifier (15). Liposomes have long been recognized as carriers for in vivo administration of active substances and drugs $(16,17)$. Market liposome formulations containing amphotericin B or doxorubicin are successful examples of the application of pharmaceutical nanotechnology to therapy.

The pharmacokinetics of liposomes composed of natural phospholipids and cholesterol is characterized by a high plasma clearance rate. These vesicles are rapidly removed from the circulation by macrophages of the reticuloendothelial system (16), an important behavior since polysaccharides are considered to modify the biological response and to act by improving the cells of the immune system.

Furthermore, it has been generally acknowledged that conventional liposomes administered by intravenous injection are rapidly removed from the circulation by macrophages. This property is a great advantage in the case of encapsulation of polysaccharides to be used as biological response modulators. The administration of glucan-loaded liposomes could enable their specific delivery to the cells of the mononuclear phagocyte system, thereby yielding an extremely efficient activation of cellular and humoral immune responses. In addition, the antischistosomial drugs praziquantel and oxamniquine encapsulated into liposomes have been reported to be greatly effective against experimental Schistosoma mansoni infection $(18,19)$.

Lectins are erythrocyte-agglutinating and sugar-specific proteins or glycoproteins, which are particularly useful tools for the investigation of carbohydrates on cell surfaces (20). In view of their capacity to recognize carbohydrates, lectins have been used as histochemical markers for cell outer-membrane glycoconjugates, especially for detecting changes that the latter undergo in malignancy (21-23), in inflammatory processes (23-25) and in parasite-host interactions $(26,27)$.

Since polysaccharide-based immunomodulators have been successful in the treatment of many parasitic infections and in view of the effectiveness of drug encapsulation into liposomes, the present study was designed to evaluate the effect of sulfated $\alpha-D$-glucan from $R$. celastri encapsulated into liposomes against an experimental model of $S$. mansoni infection. Qualitative and quantitative analyses of schistosome eggs and worm burden were evaluated in infected mice. In addition to histopathology, lectin histochemistry analyses of liver and intestine were carried out to substantiate the egg-granulomatous reaction after treatment of animals with glucan-loaded liposomes.

\section{Material and Methods}

\section{Chemicals}

Soya phosphatidylcholine (PC) was obtained from Lucas Meyer (Germany). Cholesterol (Chol), stearylamine (SA), and lectin wheat germ agglutinin (WGA), peanut agglutinin (PNA), and concanavalin A (Con A) were purchased from Sigma (USA). Chloroform and methanol were obtained from Merck (Germany). The polysaccharide $\alpha$-D-glucan was isolated from the lichen $R$. celastri (14) and sulfated according to a previously reported protocol (28) and is referred to as Glu.SO $\mathrm{S}_{4}$.

\section{Preparation of Glu.SO $\mathrm{S}_{4}$-loaded liposomes}

Liposome formulations were prepared as previously described (16), based on a lipid film formed by evaporation of solvents from an organic phospholipid solution. Positive surface-charged liposomes were prepared as follows. First lipid constituents, namely PC, Chol and SA (7:2:1, $36 \mu \mathrm{mol}$ lipids $/ 10 \mu \mathrm{L}$ buffered solution), were dissolved in 3:1 chloroform/methanol ( $\mathrm{v} / \mathrm{v})$ under moderate magnetic shaking for $15 \mathrm{~min}$.

The organic solvents were then evaporated at reduced pressure $\left(40 \mathrm{~min}\right.$ at $\left.37 \pm 1^{\circ} \mathrm{C}\right)$ with shaking at $120 \mathrm{rpm}$. Next, the dried lipid film was hydrated by the addition of an aqueous phase $(10 \mathrm{~mL})$ consisting of phosphate-buffered saline, $\mathrm{pH} 7.4$, containing $2.0 \mathrm{mg} / \mathrm{mL}$ Glu. $\mathrm{SO}_{4}$ and $2 \%$ trehalose, leading to multilamellar vesicle formation. The suspension was then kept under magnetic shaking (40 min) and sonicated at $200 \mathrm{~W}$ (40 cycles/s) for $250 \mathrm{~s}$, providing small unilamellar vesicles (SUV). Liposomes were then lyophilized using a fuel tank self-sealing system (USA) operating at 200 bar for $16 \mathrm{~h}$ with trehalose as a cryoprotectant. The product was stored in sealed vials at $4 \pm 1^{\circ} \mathrm{C}$. Liposomes with different properties were prepared by varying the lipid/ buffer ratio $(36-42 \mu \mathrm{mol} / 10 \mu \mathrm{L})$ and $\mathrm{Glu} \mathrm{SO}_{4}$ concentration $(1,1.5$ and $2 \mathrm{mg} / \mathrm{mL})$.

\section{Evaluation of the stability of $\mathrm{Glu}_{\mathrm{SO}} \mathrm{S}_{4}$-loaded liposomes (Glu.SO4-LIPO)}

The analysis of liposomes was carried out immediately after preparation of the formulations. Many features such as macroscopic and microscopic aspects, $\mathrm{pH}$ changes and Glu. $\mathrm{SO}_{4}$ encapsulation ratio were then analyzed. The $\mathrm{pH}$ evolution of Glu.SO 4 -LIPO suspensions was observed for samples stored at $4^{\circ} \mathrm{C}$ for 6 months. Liposomes were submitted to both accelerated and long-term stability tests with the aim of determining the durability of the formulations.

After preparation, liposome suspensions were submitted to centrifugation at $1300 \mathrm{~g}$ for $1 \mathrm{~h}(\mathrm{KN}-70$ centrifuge, 
Kubota, Japan), mechanical stress at 150 strokes/min at $37^{\circ} \mathrm{C}$ for $48 \mathrm{~h}$ (Polytest 20 Bioblock Scientific, France) and freeze-thawing cycles $\left(16 \mathrm{~h}\right.$ at $-18^{\circ} \mathrm{C}$ and $8 \mathrm{~h}$ at $25 \pm$ $\left.1^{\circ} \mathrm{C}\right)$. The long-term stability of lyophilized liposomes was examined for samples stored at $4 \pm 1^{\circ} \mathrm{C}$. The Glu.SO content in liposomes was assessed by the phenol-sulfuric acid method (29).

A standard calibration curve was constructed with D-glucose at concentrations ranging from 8 to $80 \mu \mathrm{g} / \mathrm{mL}$.

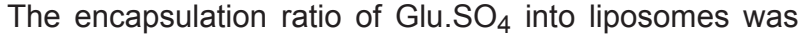
determined after ultrafiltration/ultracentrifugation at 133,570 $g$ for $1 \mathrm{~h}$ in ultra-free units (Millipore, USA). The Glu.SO concentration in the supernatant was determined as described by Frézard and de Melo (18) and the encapsulation ratio was then calculated on the basis of the total $\mathrm{Glu}_{\mathrm{SO}} \mathrm{SO}_{4}$ content in the liposome formulation.

\section{Biological activity of Glu.SO 4 -loaded liposomes}

Female albino Swiss mice aged 35-40 days and weighing $25 \pm 2$ g were percutaneously infected with 150 cercariae of S. mansoni (Biomphalaria glabrata $(\mathrm{BH})$ strain, Brazil) shed from mice experimentally infected with the $\mathrm{BH}$ strain. The animals were randomly divided into four groups of 10 mice each and treated by the intraperitoneal route with a single dose of $10 \mathrm{mg} / \mathrm{kg}$ Glu.SO 4 or Glu.SO 4 -LIPO, $24 \mathrm{~h}$ after infection. Control groups received $150 \mathrm{mM} \mathrm{NaCl}$ and empty liposomes.

The dose of $\alpha-D-g l u c a n$ and sulfated glucan was selected on the basis of LD50 data for the native polysaccharide, with results of 3200 and $400 \mathrm{mg} / \mathrm{kg}$, respectively. The test was conducted on males ( $N=15$ animals/dose) and females ( $\mathrm{N}=15$ animals/dose) for a treatment period of 30 days. The experimental doses were then selected considering the best therapeutic effect and lowest toxic potential.

Animal infection was confirmed 36 days after injection by quantitative examination of schistosome eggs in the feces, i.e., counting the number of schistosome eggs per 1 $\mathrm{g}$ of feces using the Kato-Katz thick-smear technique (30). Fifty-six days after infection, the animals were anesthetized subcutaneously with $10 \mathrm{mg} / \mathrm{kg}$ xylazine chloride and 115 $\mathrm{mg} / \mathrm{kg}$ ketamine chloride, sacrificed and submitted to portal hepatic-mesenteric perfusion. Worms were recovered and counted using a stereomicroscope and catalogued by sex. Liver and intestine samples from the animals were collected for histopathological and histochemical analyses.

\section{Ethical aspects and statistics}

The Animal Ethics Committee of Universidade Federal Rural de Pernambuco approved the experimental animal protocol. Parasitological data are summarized in the usual form, namely as means \pm SD.

Data from the different animal groups were submitted to analysis of variance (ANOVA). The Tukey test (PRISM ${ }^{\circledR}$ 3.0; Prism Corporation, USA) was applied at the $\mathrm{P}=0.05$ level of significance by assigning a letter (a, b, c, d) to each group as follows: groups with different letters indicate strong evidence for a difference between population means $(P=$ $0.05)$, while the same letters signify $P>0.05$.

\section{Histopathological analysis of Glu.SO $\mathrm{SO}_{4}$-loaded liposomes}

Qualitative and quantitative analyses of schistosome eggs and of the egg-granuloma reaction were performed in the liver of mice after treatment with $\mathrm{Glu} \mathrm{SO}_{4}$ and Glu. $\mathrm{SO}_{4}$-LIPO. The liver and small intestine biopsies were fixed in $10 \%$ formalin, routinely processed for histology and embedded in paraffin. Slices of tissue samples (4 $\mu \mathrm{m})$ were prepared on slides and treated with 3-aminepropyltriethoxy-silane (Sigma). The samples were then stained with hematoxylin-eosin and Masson trichrome. Histopathological analysis and egg-granuloma counts were performed using light microscopy (Olympus $\mathrm{BH}-2$ microscope, Japan).

Section images (100X magnification) were captured by a digital video camera (Sony, Japan) connected to the microscope and processed using the OPTIMAS ${ }^{\circledR}$ software version 6.1 (Optimas Corporation, USA). Analysis of the number of granulomas per tissue area was carried out in six random areas of hepatic tissue. Statistical analysis of the granuloma counts was performed by Tukey and Student $t$-tests $(P<0.05)$ using the PRISM 3.0 software.

\section{Lectin histochemistry of the egg-granuloma system}

Protocols were carried out as described by Beltrão et al. (21). Horseradish peroxidase (HRP)-conjugated WGA, PNA and Con A lectin were used to investigate the saccharide profile of the hepatic and intestinal schistosome egggranuloma system after treatment of S. mansoni-infected mice with free and encapsulated sulfated glucan. Tissues were deparaffinized in xylene and hydrated through graded alcohol solutions (70-100\%).

Sections $(4 \mu \mathrm{m})$ were treated with $0.1 \%(\mathrm{w} / \mathrm{v})$ trypsin for $2 \mathrm{~min}$ at $37^{\circ} \mathrm{C}$, followed by $0.3 \%(\mathrm{v} / \mathrm{v})$ methanolic hydrogen peroxide for 2 min at $25^{\circ} \mathrm{C}$ and incubated with $100 \mu \mathrm{g} / \mathrm{mL}$ conjugated lectins (WGA-HRP, PNA-HRP and Con A-HRP) for $2 \mathrm{~h}$ at $4^{\circ} \mathrm{C}$. Sections were then washed twice (5 min) with $10 \mathrm{mM}$ phosphate-buffered saline (PBS), $\mathrm{pH} 7.2$, containing $0.15 \mathrm{M} \mathrm{NaCl}$ after each step. The peroxidase reaction was visualized using a solution of diaminobenzidine and hydrogen peroxide in PBS. Inhibition assays of lectin-carbohydrate recognition were performed using the corresponding lectin-specific sugar: Nacetyl-glucosamine for WGA, D-galactose for PNA and methyl-a-D-mannoside for Con A, at a final concentration of $300 \mathrm{mM}$. Tissue sections were counterstained with hematoxylin and evaluated by light microscopy (Olympus $\mathrm{BH}-2$, Japan). Intense brown staining is visualized in the neighborhood of egg-granulomas as a result of the formation of lectin-carbohydrate conjugates. 


\section{Results}

\section{Stability of Glu.SO-loaded liposomes}

The liposomes obtained were classified morphologically as SUV obtained by sonication to reduce their size and were positively charged.

Liposome suspensions were submitted to mechanical and centrifuge resistance testing and all were found to be stable, except for F6, which presented precipitation after both tests (Table 1). The most stable formulation was F4 prepared with $36 \mu \mathrm{mol}$ lipids $/ 10 \mu \mathrm{L}$ and $2 \mathrm{mg} / \mathrm{mL}$ Glu. $\mathrm{SO}_{4}$, which remained stabilized, with no physicochemical changes being noticed after six freeze-thaw cycles. Furthermore, after redispersion the lyophilized F4 formulation presented a macroscopic and microscopic appearance similar to that of the suspension form. This preparation was then chosen for further studies.
The F4 formulation (suspension form) showed a slight gradual decrease in $\mathrm{pH}$ value from 7.4 to 6.5 when stored at $4 \pm 1^{\circ} \mathrm{C}$ over a period of 180 days (Figure 1). This might be a sign of slow lipid degradation inducing fatty acid formation. A study by Pontes et al. (31) had already shown that the main degradation pathway for a lipid medium leads to the formation of fatty acids, interfering with the electrical conductivity and gradually reducing the $\mathrm{pH}$ of the preparations. On the other hand, lyophilized Glu.SO $\mathrm{SO}_{4}$ LIPO presented no $\mathrm{pH}$ changes after redispersion. A Glu. $\mathrm{SO}_{4}$ encapsulation ratio of $50 \%$ was achieved, which can be considered satisfactory for in vivo studies with the Glu. $\mathrm{SO}_{4}$-LIPO formulation.

\section{Efficacy of Glu.SO4-loaded liposomes on experimental schistosomiasis}

Figure 2 shows the schistosome egg count in feces of

Table 1. Evaluation of the short- and long-term stability of sulfated polysaccharide $\alpha$-D-glucan encapsulated into liposomes (Glu.SO $\mathrm{SO}_{4}$-LIPO).

\begin{tabular}{lccccc}
\hline $\begin{array}{l}\text { LIPO } \\
\text { formulations }\end{array}$ & $\begin{array}{c}\text { Lipid/buffer } \\
(\mu \mathrm{mol} / 10 \mu \mathrm{L})\end{array}$ & $\begin{array}{c}\mathrm{Glu} . \mathrm{SO}_{4} \\
(\mathrm{mg} / \mathrm{mL})\end{array}$ & $\begin{array}{c}\text { Mechanical stress } \\
\left(150 \text { strokes } \cdot \mathrm{min}^{-1} \cdot 24 \mathrm{~h}^{-1}\right)\end{array}$ & $\begin{array}{c}\text { Centrifugation } \\
(3000 \mathrm{rpm}, 1 \mathrm{~h})\end{array}$ & $\begin{array}{c}\text { Freeze-thawing } \\
\text { cycles }^{*}\end{array}$ \\
\hline F1 & 36 & 0 & Stable & Stable & 1 \\
F2 & 36 & 1 & Stable & Stable & 1 \\
F3 & 36 & 1.5 & Stable & Stable & 1 \\
F4 & 36 & 2 & Stable & Stable & $>6$ \\
F5 & 32 & 0 & Stable & Stable & 1 \\
F6 & 32 & 2 & Precipitate & Precipitate & 2 \\
F7 & 42 & 0 & Stable & Precipitate & 4 \\
F8 & 42 & 1 & Stable & Stable & 4 \\
\hline
\end{tabular}

${ }^{*}\left(-18^{\circ} \mathrm{C}\right.$ for $16 \mathrm{~h} ; 25^{\circ} \mathrm{C}$ for $\left.8 \mathrm{~h}\right)$.

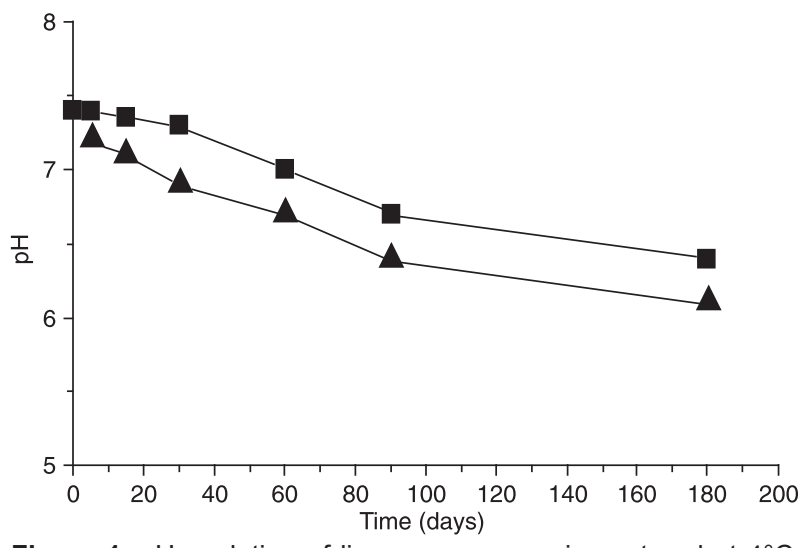

Figure 1. $\mathrm{pH}$ evolution of liposome suspensions stored at $4^{\circ} \mathrm{C}$. Squares, Sulfated glucan encapsulated into liposomes (Glu. $\mathrm{SO}_{4-}$ LIPO); triangles, empty liposomes.

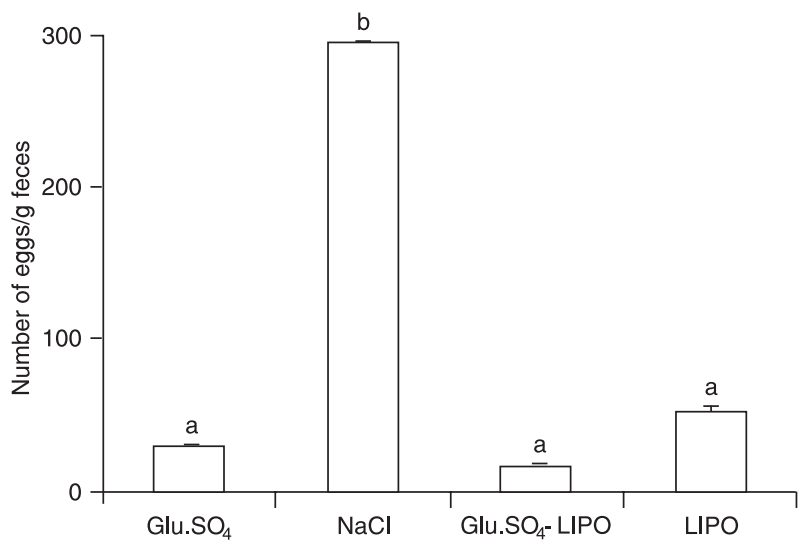

Figure 2. Effect of treatments against oviposition by Schistosoma mansoni (eggs/g feces after 56 days of mouse infection). Glu.

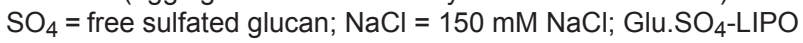
$=$ sulfated glucan encapsulated into liposomes; LIPO = empty liposomes. Different letters mean a statistically significant difference between groups ( $\mathrm{P} \leq 0.05$, Tukey and Student $t$-tests). 
treated S. mansoni-infected mice after 56 days of infection. Treatment of the animals with $\mathrm{Glu} \mathrm{SO}_{4}$ produced a significant reduction in S. mansoni infection expressed by an egg elimination of $90.1 \%(P=0.002)$ in comparison with the untreated control group. However, no significant difference was observed between groups treated with Glu. $\mathrm{SO}_{4}$ or Glu.SO $\mathrm{SO}_{4}$-LIPO. These data were obtained using a single dose.

Analysis of worms recovered from the portal hepaticmesenteric plexus is shown in Table 2. A statistically significant reduction in the number of male and female worms was observed in the animal groups treated with $\mathrm{Glu} \mathrm{SO}_{4}(73$ and $71 \%$ ) and Glu.SO 4 -LIPO (86 and 91\%), respectively, compared to control.

\section{Histopathological analysis of the liver}

The histopathological analysis of the liver of animals treated with Glu.SO $\mathrm{SO}_{4}$ and Glu.SO 4 -LIPO is shown in Figure 3 . The group treated with free polysaccharide showed

Table 2. Effect of treatment with sulfated polysaccharide a-D-

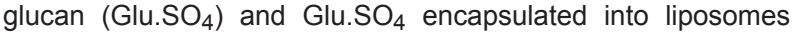
(Glu.SO ${ }_{4}$-LIPO) (10 mg/kg, ip, $24 \mathrm{~h}$ after infection) on Schistosoma mansoni adult worm recovery from infected mice after 56 days of infection.

\begin{tabular}{|c|c|c|c|c|}
\hline \multirow[t]{2}{*}{ Animal treatment } & \multicolumn{2}{|c|}{ Adult worm recovery } & \multicolumn{2}{|c|}{ \% Efficacy } \\
\hline & Male & Female & Male & Female \\
\hline $\mathrm{NaCl}(150 \mathrm{mM})$ & $21.8 \pm 3.7^{b}$ & $18.6 \pm 5.1^{\mathrm{b}}$ & - & - \\
\hline Glu. $\mathrm{SO}_{4}$ & $5.8 \pm 1.9^{a}$ & $5.4 \pm 3.4^{a}$ & 73.4 & 71.0 \\
\hline Glu.SO $\mathrm{SO}_{4}$-LIPO & $3.0 \pm 1.1^{\mathrm{c}}$ & $1.75 \pm 0.5^{c}$ & 86.2 & 90.6 \\
\hline Empty liposomes & $4.8 \pm 1.5^{a}$ & $4.4 \pm 1.5^{a}$ & - & - \\
\hline
\end{tabular}

Means followed by different superscript letters were significantly different $(P \leq 0.05$, Tukey test). a statistically significant $61 \%$ reduction in the number of hepatic granulomas $(P=0.007336)$ compared to control. In the polysaccharide-encapsulated group, the reduction in the number of hepatic granulomas was significantly different from the empty liposome group, with a $63 \%$ decrease $(P=0.029527)$.

Furthermore, histopathological analysis of the tissue showed various aspects of the stages of evolution of the egg-granuloma system, with extensive areas of necrosis and degenerated eggs being observed in the liver.

\section{Lectin histochemical analysis of the egg-granuloma system}

The lectin histochemistry results (Table 3 ) showed that WGA, specific for N-acetyl-glucosamine, bound intensely to cells in the egg-granuloma system in both the hepatic and intestinal tissue of all experimental animal groups. PNA, which binds specifically to D-galactose, produced an intense staining pattern in cells treated with empty li-

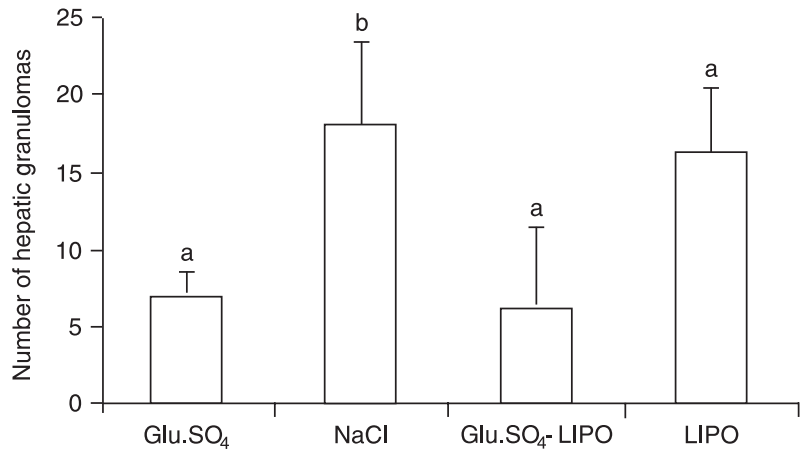

Figure 3. Histopathological analyses (hepatic granulomas) of liver of mice infected with Schistosoma mansoni. Glu. $\mathrm{SO}_{4}=$ free sulfated glucan; $\mathrm{NaCl}=150 \mathrm{mM} \mathrm{NaCl} ; \mathrm{Glu}^{-S} \mathrm{O}_{4}$-LIPO = sulfated glucan encapsulated into liposomes; LIPO = empty liposomes. Different letters mean a statistically significant difference between groups ( $\mathrm{P} \leq 0.05$, Tukey and Student $t$-tests).

Table 3. Histochemical profile of lectin staining in the egg-granuloma system in the liver and intestine of animals treated with free sulfated glucan (Glu.SO $\mathrm{SO}_{4}$ ) and sulfated glucan encapsulated into liposomes (Glu.SO 4 -LIPO).

\begin{tabular}{|c|c|c|c|c|c|c|}
\hline \multirow[t]{3}{*}{ Animal treatment } & \multicolumn{6}{|c|}{ Horseradish peroxidase-conjugated lectins } \\
\hline & \multicolumn{2}{|c|}{ HRP-WGA (N-acetyl-glucosamine) } & \multicolumn{2}{|c|}{ HRP-PNA (D-galactose) } & \multicolumn{2}{|c|}{ HRP-Con A (D-mannose; D-glucose) } \\
\hline & Liver & Intestine & Liver & Intestine & Liver & Intestine \\
\hline $\mathrm{NaCl}(150 \mathrm{mM})$ & + & + & + & + & - & - \\
\hline Glu. $\mathrm{SO}_{4}$ & + & + & + & + & + & + \\
\hline Glu.SO $\mathrm{SO}_{4}$-LIPO & + & + & - & - & - & - \\
\hline Empty liposomes & + & + & - & - & - & - \\
\hline
\end{tabular}

$\mathrm{NaCl}$ and empty liposomes were used as controls. $(+)=$ reactive; $(-)=$ non-reactive. HRP-WGA = horseradish peroxidase-wheat germ agglutinin; HRP-PNA = horseradish peroxidase-peanut agglutinin; HRP-Con A = horseradish peroxidase-concanavalin A. 
posomes, whereas no reactivity was observed in the Glu. $\mathrm{SO}_{4}$-LIPO-treated group. Con $\mathrm{A}$, which recognizes a-Dmannose and $\mathrm{D}$-glucose residues in cell glycoconjugates, stimulated intense cytoplasmic staining in both the liver and intestine egg-granuloma systems only in the group treated with Glu.SO $\mathrm{S}_{4}$.

Figure 4 illustrates the lectin histochemical staining patterns of the egg-granuloma system in the liver $(A)$ and intestine (B) of animals treated with $\mathrm{Glu} \mathrm{SO}_{4}$. Commercial lectins (WGA, PNA and Con A) conjugated to peroxidase were used. The figure is representative of HRP-PNA, with no reactive staining of intestinal egg-granulomas in animals treated with Glu.SO $\mathrm{SO}_{4}$-LIPO.

\section{Discussion}

In the present study, sulfated glucan from $R$. celastri was successfully encapsulated into positively charged liposomes prepared with PC, Chol, SA (7:2:1) and Glu. $\mathrm{SO}_{4}(2 \mathrm{mg} / \mathrm{mL})$, with an encapsulation efficiency of $50 \%$. The efficacy of Glu.SO $\mathrm{SO}_{4}$-LIPO was tested in experimental S. mansoni infection.

The choice of cholesterol and stearylamine (lipid laden) is justified by the fact that these compounds increase the rate of encapsulation, increasing the capture of the drug since the literature (31) shows that the rate of SUV liposome encapsulation is low (30-35\%). Our results confirmed these data since we obtained an encapsulation rate of $50 \%$ of the formulation when we used liposomes loaded with cholesterol and lipids.

Glu. $\mathrm{SO}_{4}$ presented an almost identical efficacy as its liposomal form in the elimination of $S$. mansoni eggs and worm burden and in hepatic granuloma development. Despite its relatively low encapsulation rate, the efficacy of sulfated glucan was improved as a result of encapsulation into liposomes. As a result, liposomes should be more efficient in activating macrophages, thereby reducing the parasitic infection. Furthermore, it should be pointed out that treatment with sulfated glucan, free or encapsulated, induced a remarkable decrease in granuloma development, which was mainly characterized by an inflammatory reaction of the host against the antigens released by parasite eggs (32).

Granulomas are areas of cellular infiltration consisting mainly of eosinophils, macrophages, fibroblasts, and lymphocytes. The development of granulomas around tissuetrapped eggs is the pathogenic feature of murine schistosomiasis. Hepatotoxic molecules are released by schistosome eggs, including a 31-kDa glycoprotein termed W1 (8). In fact, granulomas may act as sequesters of toxic molecules released by eggs, thus preventing liver damage.

These findings suggest an immunological activity of a-Glu. $\mathrm{SO}_{4}$. In fact, it is well known that polysaccharides from bacteria or yeast are able to stimulate the mononuclear phagocyte system and improve host resistance to viral, bacterial and parasitic infections. As reported, a polysaccharide such as lentinan, a (1.3)-ß-D-glucan from the cell wall of Lentinus edodes, presented antitumor activity $(33,34)$. This activity was attributed to the increase in $\mathrm{T}$ cells, macrophages, $\mathrm{CD}^{+}, \mathrm{CD}^{+}$, and natural killer cells. Furthermore, lentinan induced an increase in the production of interleukin-1 (IL-1) and tumor necrosis factor- $\alpha$ (TNF- $\alpha$ ) by monocytes (35). Moreover, schistosomiasis, as is the case with most chronic infections, develops a complex tightly regulated host and a balanced immune response that includes type-1 and type-2 components (32).

Animals treated with Glu.SO 4 -LIPO or Glu.SO $\mathrm{SO}_{4}$ exhibited a lectin histochemical profile rather different from
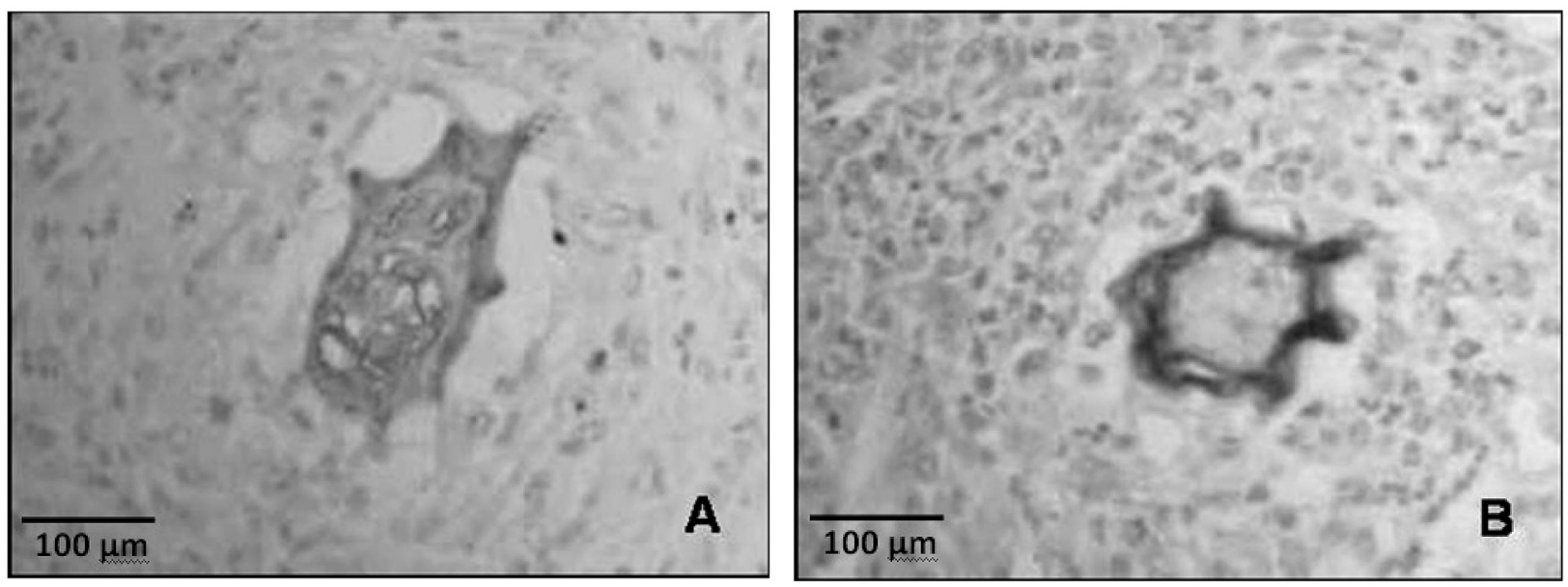

Figure 4. Histochemical profile of lectin staining in the egg-granuloma system in the liver $(A)$ and intestine (B) of animals treated with free sulfated glucan $\left(\mathrm{Glu}_{\mathrm{SO}}\right.$ ), which exhibited horseradish peroxidase-wheat germ agglutinin and horseradish peroxidase-peanut agglutinin lectins, respectively. Magnification 400X. 
that of the control groups. The relationship between these results and the histopathological findings, which showed that treatment with free or encapsulated $\mathrm{Glu}_{\mathrm{SO}} \mathrm{SO}_{4}$ drastically decreased the number of liver and intestine granulomas, suggests that the different glycosylation of components in the egg-granuloma system may be linked to the decreased number of granulomas.

Insights were provided by lectin histochemistry using HRP-WGA, HRP-PNA and HRP-Con A because different staining patterns were observed in egg-granuloma systems as a function of the treatment and tissues analyzed. These findings are related to the carbohydrate profile of cell membrane glycoconjugates where glucose, mannose, $\mathrm{N}$ acetyl-glucosamine, and galactose residues are distributed differently in the cell membrane.

A number of studies have emphasized the significance of the encapsulation of antischistosomal drugs into liposomes and the action of such systems on clinical drugs. Important results have been reported in a study in which mice received subcutaneous prophylactic treatment with free and liposome-encapsulated praziquantel before S. mansoni infection (36). The drug encapsulated into liposomes had a powerful prophylactic action in the treated animals, which had a longer survival and a remarkable reduction of hepatic worms compared to the untreated animals. Another study described the encapsulation of oxamniquine into conventional liposomes (18). Oxamniquine, a well-known schistosomicide that acts by inhibiting nucleic synthesis and promoting irreversible alkylation of schistosomal DNA (2), was encapsulated into conventional liposomes (LOXA). When the effectiveness of LOXA was tested on experimental S. mansoni infection a significant reduction

\section{References}

1. Chitsulo L, Engels D, Montresor A, Savioli L. The global status of schistosomiasis and its control. Acta Trop 2000; 77: 41-51.

2. Harder A. Chemotherapeutic approaches to schistosomes: current knowledge and outlook. Parasitol Res 2002; 88: 395-397.

3. Hirose $\mathrm{Y}$, Kirinoki M, Matsuda H. Efficacy of administration of praziquantel on 2 days 2 weeks apart against Schistosoma japonicum eggs in mice. Parasitol Int 2003; 52: 141-146.

4. Pica-Mattoccia L, Cioli D. Sex- and stage-related sensitivity of Schistosoma mansoni to in vivo and in vitro praziquantel treatment. Int J Parasitol 2004; 34: 527-533.

5. Cioli D. Praziquantel: is there real resistance and are there alternatives? Curr Opin Infect Dis 2000; 13: 659-663.

6. Botros S, Pica-Mattoccia L, William S, El-Lakkani N, Cioli D. Effect of praziquantel on the immature stages of Schistosoma haematobium. Int J Parasitol 2005; 35: 1453-1457.

7. Coelho PM, Lima e Silva FC, Nogueira-Machado JA. Resistance to oxamniquine of a Schistosoma mansoni strain isolated from patient submitted to repeated treatments. Rev Inst Med Trop São Paulo 1997; 39: 101-106. in the total number of worms was observed in the treated group compared to the control group, which was treated with free oxamniquine or empty liposomes.

The maximum effect of LOXA $(97 \%$ reduction in parasite load) was achieved when the preparation was administered 1 day after infection, although similar results were not achieved with free oxamniquine under similar conditions. The encapsulation of these two antischistosomal drugs was thus beneficial for the treatment of experimental schistosomiasis. Although the mode of action of most schistosomicidal drugs is still not understood, experimental evidence indicates that their capacity to kill adult Schistosoma worms is dependent on the immune responsiveness of the host (9), especially regarding praziquantel.

Based on these findings, we may speculate that the sulfated glucan from $R$. celastri has immune potentiating activity and could be used in combined treatment with oxamniquine or praziquantel in order to improve the host immune response and the schistosomicidal activity of the drug. Indeed, the exact mechanism of action of the sulfated $\alpha$-glucan from $R$. celastri remains to be elucidated by further immunological investigations.

\section{Acknowledgments}

N.S. Santos-Magalhães and L.B. Carvalho Jr. were recipients of grants from CNPq (\#334946-01 and \#301735-4, respectively). R.V.S. Araújo was supported by CNPq MSc scholarships. Research partially supported by the Brazilian Network of Research on Nanobiotechnology - Nanobiotec CNPq/MCT and by the CNPq-PRONEX Research Program (Carbohydrate Structure and Properties, UFPR).

8. Dunne DW, Hagan P, Abath FG. Prospects for immunological control of schistosomiasis. Lancet 1995; 345: 14881491.

9. Fallon PG, Cooper RO, Probert AJ, Doenhoff MJ. Immunedependent chemotherapy of schistosomiasis. Parasitology 1992; 105 (Suppl): S41-S48.

10. McCarthy JS, Nutman TB. Perspective: prospects for development of vaccines against human helminth infections. $J$ Infect Dis 1996; 174: 1384-1390.

11. Tseng CC, Shang HF, Wang LF, Su B, Hsu CC, Kao HY, et al. Antitumor and immunostimulating effects of Anoectochilus formosanus Hayata. Phytomedicine 2006; 13: 366-370.

12. Popov SV, Popova GY, Ovodova RG, Bushneva OA, Ovodov YS. Effects of polysaccharides from Silene vulgaris on phagocytes. Int J Immunopharmacol 1999; 21: 617-624.

13. Stuelp-Campelo PM, Carneiro-Leão AMA, Gorin PAJ, lacomini M. The glucans of Ramalina celastri: relation with chemotypes of other lichens. Carbohy Pol 1999; 40: 101106.

14. Leao AM, Buchi DF, lacomini M, Gorin PA, Oliveira MB. Cytotoxic effect against HeLa cells of polysaccharides from the 
lichen Ramalina celastri. J Submicrosc Cytol Pathol 1997; 29: 503-509.

15. Stuelp-Campelo PA, Oliveira MBM, Carneiro-Leão AMA, Carbonero ER, Gorin PAJ, lacomini M. Effect of a soluble $\alpha$-D-glucan from the lichenized fungus Ramalina celastri on macrophage activity. Int J Immunopharmacol 2002; 2: 691698.

16. Andrade CA, Correia MT, Coelho LC, Nascimento SC, Santos-Magalhaes NS. Antitumor activity of Cratylia mollis lectin encapsulated into liposomes. Int J Pharm 2004; 278: 435-445.

17. Torchilin VP. Recent advances with liposomes as pharmaceutical carriers. Nat Rev Drug Discov 2005; 4: 145-160.

18. Frezard F, de Melo AL. Evaluation of the schistosomicidal efficacy of liposome-entrapped oxamniquine. Rev Inst Med Trop São Paulo 1997; 39: 97-100.

19. Mourao SC, Costa PI, Salgado HR, Gremiao MP. Improvement of antischistosomal activity of praziquantel by incorporation into phosphatidylcholine-containing liposomes. Int J Pharm 2005; 295: 157-162.

20. Sharon $\mathrm{N}$, Lis $\mathrm{H}$. History of lectins: from hemagglutinins to biological recognition molecules. Glycobiology 2004; 14: 53R-62R.

21. Beltrao El, Medeiros PL, Rodrigues OG, Figueredo-Silva J, Valenca MM, Coelho LC, et al. Parkia pendula lectin as histochemistry marker for meningothelial tumour. Eur J Histochem 2003; 47: 139-142.

22. Rêgo MJBM, Santos LX, Carvalho Junior LB, Beltrão EIC, Sobral APV. Lectin histochemistry of mucoepidermoid carcinoma. Oral Oncol 2005; 1: 178-179.

23. Melo-Júnior MR, Araújo-Filho JLS, Patu VJRM, Machado MCFP, Beltrão EIC, Carvalho LB Jr. Digital image analysis of skin neoplasms evaluated by lectin histochemistry: potential marker to biochemical alterations and tumour differential diagnosis. J Bras Patol Med Labor 2006; 42: 455-460.

24. Wroblewski S, Berenson M, Kopeckova P, Kopecek J. Potential of lectin-N-(2-hydroxypropyl)methacrylamide copolymer-drug conjugates for the treatment of pre-cancerous conditions. J Control Release 2001; 74: 283-293.

25. Melo-Júnior MR, Telles MAS, Albuquerque FB, Pontes Filho NT, Carvalho-Jr LB, Beltrão EIC. Altered lectin-binding sites in normal colon and ulcerative colitis. J Bras Patol Med Lab 2004; 2: 123-125.
26. Nyame AK, Leppanen AM, Bogitsh BJ, Cummings RD. Antibody responses to the fucosylated LacdiNAc glycan antigen in Schistosoma mansoni-infected mice and expression of the glycan among schistosomes. Exp Parasitol 2000; 96: 202-212.

27. Melo-Júnior MR, Cavalcanti CLB, Pontes-Filho NT, CarvaIho-Jr LB, Beltrão EIC. Lectin staining patterns in human gastric mucosae with and without exposure to Helicobacter pylori. Braz J Microbiol 2008; 39: 1-7.

28. Martinichen-Herrero JC, Carbonero ER, Gorin PAJ, lacomini M. Anticoagulant and antithrombotic activity of a sulfate obtained from a glucan component of the lichen Parmotrema mantiqueirense Hale. Carbohyd Pol 2005; 60: 7-13.

29. Dubois M, Gilles KA, Hamilton JK, Rebers PA, Smith F. Colorimetric method for determination of sugars and related substances. Anal Chem 1956; 28: 350.

30. Katz NA. Simple device for quantitative determination of Schistosoma mansoni eggs in faeces examined by the thicksmear technique. Rev Inst Med Trop São Paulo 1972; 14: 397-400.

31. Pontes ACO, Caetano MNP, Santos-Magalhães NS. Physico-chemical characterization and antimicrobial activity of benzathine penicillin G liposomes, STP. Pharm Sci 1999; 9: 419-427.

32. Brunet LR, Dunne DW, Pearce EJ. Cytokine interaction and immune responses during Schistosoma mansoni infection. Parasitol Today 1998; 14: 422-427.

33. Haba S, Hamaoka T, Takatsu K, Kitagawa M. Selective suppression of T-cell activity in tumor-bearing mice and its improvement by lentinan, a potent anti-tumor polysaccharide. Int J Cancer 1976; 18: 93-104.

34. Hamuro J, Rollinghoff M, Wagner H. Beta(1 leads to 3) glucan-mediated augmentation of alloreactive murine cytotoxic T-lymphocytes in vivo. Cancer Res 1978; 38: 3080-3085.

35. Arinaga S, Karimine N, Takamuku K, Nanbara S, Nagamatsu $\mathrm{M}$, Ueo $\mathrm{H}$, et al. Enhanced production of interleukin 1 and tumor necrosis factor by peripheral monocytes after lentinan administration in patients with gastric carcinoma. Int J Immunopharmacol 1992; 14: 43-47.

36. El-Ridy A, Ghorab M, Ghorab MM. Evaluation of the antischistosomal effect of praziquantel in a liposomal delivery system in mice. Int J Pharmac 1994; 103: 237-241. 